\title{
Letter to the Editor: Effects of Bariatric Surgery on Cancer Risk
}

\author{
Markku Peltonen $^{1}$ (D) $\cdot$ Magdalena Taube $^{2} \cdot$ Lena MS Carlsson $^{2}$
}

Published online: 15 February 2020

(C) Springer Science+Business Media, LLC, part of Springer Nature 2020

\section{Dear Editor}

We read with interest the recent meta-analysis by Zhang et al. on the effects of bariatric surgery on cancer risk[1]. Two publications from the prospective, controlled Swedish Obese Subjects (SOS) study were included in the analysis; one on cancer mortality [2] and one on female-specific cancer incidence [3]. However, the main publication on cancer incidence from the SOS study was for some reason excluded [4].

Second, it would have been interesting to see the metaanalysis separately for men and women, as an intriguing sex difference in the effectiveness of bariatric surgery regarding cancer has been observed, with major effect in women and virtually no effect in men $[4,5]$.

Cancer is a heterogenous disease group, with differences in risk factors and treatment responses. The effect of bariatric surgery on cancer risk is variable-as demonstrated in the literature - and additional studies analyzing the effects on specific cancer types are needed. To further increase the knowledge in this field, we have recently published one such study, evaluating the effects of bariatric surgery on skin cancer [6].

Markku Peltonen

markku.peltonen@thl.fi

1 National Institute for Health and Welfare, Mannerheimintie 166, Helsinki, Finland

2 The Sahlgrenska Academy at University of Gothenburg, Gothenburg, Sweden

\section{Compliance with Ethical Standards}

Conflict of Interest Dr. Carlsson reports personal fees from Johnson\&Johnson, outside the submitted work. Dr. Taube has nothing to disclose. Dr. Peltonen has nothing to disclose.

\section{References}

1. Zhang K, Luo Y, Dai H, Deng Z. Effects of bariatric surgery on cancer 37 risk: evidence from meta-analysis. Obes Surg. 2020; https://doi.org/10.1007/s11695-019-04368-4.

2. Sjöström L, Narbro K, Sjöström CD, et al. Effects of bariatric surgery on mortality in Swedish obese subjects. N Engl J Med. 2007;357(8): $741-52$.

3. Anveden $\AA$, Taube M, Peltonen M, et al. Long-term incidence of female-specific cancer after bariatric surgery or usual care in the Swedish Obese Subjects Study. Gynecol Oncol. 2017;145:224-9.

4. Sjöström L, Gummesson A, Sjöström D, et al. Effects of bariatric surgery on cancer incidence in obese patients in Sweden (Swedish obese subjects study): a prospective, controlled intervention trial. Lancet Oncol. 2009;10:653-62.

5. Renehan AG. Bariatric surgery, weight reduction, and cancer prevention. Lancet Oncol. 2009;10:640-1.

6. Taube M, Peltonen M, Sjöholm K, et al. Association of bariatric surgery with skin cancer incidence in adults with obesity: a nonrandomized controlled trial. JAMA Dermatol. 2020;156(1):3843. https://doi.org/10.1001/jamadermatol.2019.3240.

Publisher's Note Springer Nature remains neutral with regard to jurisdictional claims in published maps and institutional affiliations. 